\title{
Analisa dan Perancangan Website Media Sosial (Studi Kasus Program Studi Informatika Universitas Sam Ratulangi)
}

\author{
Mohamad Harly Jamad Hamzah, Viriginia Tulenan, Xaverius B. N. Najoan \\ Teknik Informatika Universitas Sam Ratulangi , Manado-95115, Indonesia. \\ Email: 110216036@student.unsrat.ac.id, virginia.tulenan@unsrat.ac.id, xnajoan@unsrat.ac.id
}

\begin{abstract}
Abstrak - Pada Program Studi Informatika UNSRAT sudah mempunyai media komunikasi seperti Portal Akademik dan E-Learning, akan tetapi pemberian informasinya masih kurang efektif. Saat ini berbagai media sosial berkembang di Indonesia, ini menandakan bahwa orang-orang makin giat untuk bersosialisasi satu sama lainya, untuk itu Prodi Informatika UNSRAT membutuhkan media sosial sendiri untuk interaksi antar mahasiswa dan dosen. Metode yang digunakan adalah WebML (Web Modeling Languange) yang dalam prosesnya Data design dan Hypertext design merupakan hal yang paling berpengaruh dalam pembuatan website. Pengguna website media sosial ini adalah mahasiswa, dosen dan alumni yang ada pada Program Studi Informatika UNSRAT dengan konten medsos yang memiliki sejumlah aspek fungsional seperti identitas, percakapan (interaksi), berbagi (sharing), hubungan (relasi), reputasi (status) dan kelompok (group). Agar dapat digunakan untuk berinteraksi sosial antar sesama mahasiswa, atau mahasiswa dan dosen. Hasil dari penelitian ini adalah rancangan database dan tampilan website untuk dilanjutkan oleh pengembang sampai pada tahap Implementation.
\end{abstract}

Kata kunci : Media, Sosial, WebML, Perancangan, Informatika, UNSRAT.

\section{PENDAHULUAN}

Teknologi internet saat ini berkembang dengan cepat, hal ini berpengaruh juga terhadap perkembangan website media sosial. Ciri khas alami manusia adalah suka untuk berinteraksi sosial antar individu baik kepada teman, kerabat maupun keluarga. Sehingga hal ini tentu memicu penggunaan teknologi dikarenakan waktu untuk hubungan secara tatap muka langsung semakin sulit dilakukan. Penggunaan media sosial sudah mulai bergeser dari sekedar untuk kontak sosial dan sekarang sudah saling mengirimkan pesan secara online. Hubungan informasi ini seperti grup yang membahas bidang tertentu, penjualan barang, hingga diskusi atau rapat untuk mengadakan acara (event)

Pada tahun 2014 Tim Pusat Humas Kementerian Perdagangan RI menjelaskan bahwa media sosial bisa dikatakan sebagai media online, di mana para penggunanya (user) melalui aplikasi berbasis internet dapat berbagi, berpartisipasi, dan menciptakan konten berupa blog, wiki, forum, jejaring sosial dan ruang dunia virtual yang disokong oleh teknologi multimedia yang kian canggih. Merebaknya situs medsos yang muncul menguntungkan banyak orang dari berbagai belahan dunia untuk berinteraksi dengan mudah dan dengan ongkos yang murah ketimbang memakai telepon. Dampak positif yang lain dari adanya situs jejaring sosial adalah percepatan penyebaran informasi ${ }^{[5]}$

Saat ini berbagai media sosial berkembang di Indonesia. Ini menandakan bahwa orang-orang makin giat untuk bersosialisasi satu sama lainya. Salah satu media sosial yang asli dari Indonesia adalah Sebangsa. Di jelaskan dalam website sebangsa.com, Sebangsa merupakan platform media sosial pertama didunia yang mentransformasi layanan publik yang sudah ada menjadi sebuah layanan partisipatif dengan memanfaatkan teknologi mobile. Media sosial ini bisa dibilang mirip Path dan Twitter dengan fitur linimasa yang bisa juga mengupdate status, foto dan kegiatan lainnya. Tidak hanya itu, fitur menarik Sebangsa adalah menghubungkan pengguna dengan berbagai layanan publik seperti kepolisian dan pemadam kebakaran. Selain itu, terdapat pula fitur Pesan Panik yang berfungsi mengirimkan pesan kepada 5 orang terdekat apabila dalam keadaan darurat. Fitur Pesan jaga-jaga yang memungkinkan posisi pengguna bisa diketahui oleh 5 orang terdekatnya dengan mengaktifkan GPS. ${ }^{[8]}$

Pada Program Studi (Prodi) Informatika Universitas Sam Ratulangi (UNSRAT) sudah mempunyai media komunikasi seperti Portal Akademik dan E-Learning. Salah satu permasalahan yang sering terjadi di kalangan mahasiswa khususnya dalam Prodi Informatika UNSRAT adalah kurang efektifnya pemberian informasi yang diberikan oleh dosen kepada mahasiswa, hal tersebut dikarenakan informasi hanya diberikan oleh dosen kepada salah satu mahasiswa untuk disebarkan kepada mahasiswa lainnya sehingga informasi yang didapat sering simpang siur. Media sosial yang digunakan oleh hampir semua kalangan saat ini dapat dimanfaatkan untuk mengatasi permasalahan tidak efektifnya pemberian informasi tersebut, sehingga pemberian tugas, perubahan jadwal kuliah, pengumuman kegiatan dan lain sebagainya dapat 
langsung diumumkan melalui media sosial. Akan tetapi dibutuhkan satu perancangan media sosial yang khusus untuk kegiatan perkuliahan sekaligus interaksi yang melibatkan dosen dan mahasiswa yang ada di Prodi Informatika UNSRAT.

Berdasarkan uraian tersebut penulis berinisiatif untuk membuat sebuah penelitian yang membahas tentang analisa dan perancangan website media sosial Prodi Informatika UNSRAT dengan konten medsos yang memiliki sejumlah aspek fungsional seperti identitas, percakapan (interaksi), berbagi (sharing), kehadiran (eksis), hubungan (relasi), reputasi (status) dan kelompok (group). Agar dapat digunakan untuk berinteraksi sosial antar sesama mahasiswa, atau mahasiswa dan dosen.

\section{A. Rumusan Masalah}

Setelah melihat latar belakang yang ada, maka penulis dapat merumuskan masalah sebagai berikut.

- Bagaimana merancang website Media Sosial untuk interaksi mahasiswa dan dosen yang ada di Prodi Informatika UNSRAT?

\section{B. Batasan Masalah}

Batasan masalah dari penelitian ini antara lain:

- Lingkungan Penelitian hanya dilakukan pada Program Studi Informatika UNSRAT

- Dalam metode WebML perancangan hanya sampai pada tahap hypertext design

- Fitur yang dirancang berupa sharing informasi seperti Fitur Tanya Jawab, Pengumuman, Pesan, dan Grup.

\section{Tujuan Penelitian}

Tujuan dari penelitian ini adalah untuk merancang Website Media Sosial Prodi Informatika UNSRAT untuk interaksi mahasiswa dan dosen agar lebih efisien.

\section{Manfaat Penelitian}

Adapun tujuan dari penelitian ini, antara lain:

- Bagi Program Studi Informatika UNSRAT mendapatkan acuan dalam mengembangkan website media sosial Prodi Informatika UNSRAT.

- Bagi penulis dapat mengembangkan ilmu yang dipelajari dan mengiimplementasikannya pada lingkungan masyarakat

\section{LANDASAN TEORI}

\section{A. Media Sosial (Social Media)}

Pada Tahun 2013 Faizah Alkaff, dkk berpendapat bahwa media sosial adalah sebuah media online, dengan para penggunanya bisa dengan mudah berpartisipasi, berbagi, dan menciptakan isi meliputi blog, jejaring sosial, wiki, forum dan dunia virtual. Blog, jejaring sosial dan wiki merupakan bentuk media sosial yang paling umum digunakan oleh masyarakat di seluruh dunia. Pendapat lain mengatakan bahwa media sosial adalah media online yang mendukung interaksi sosial dan media sosial menggunakan teknologi berbasis web yang mengubah komunikasi menjadi dialog interaktif.

Media sosial mengajak siapa saja yang tertarik untuk berpertisipasi dengan memberi kontribusi dan feedback secara terbuka, memberi komentar, serta membagi informasi dalam waktu yang cepat dan tak terbatas. Media sosial mempunyai ciri-ciri, yaitu sebagai berikut:

- Pesan yang di sampaikan tidak hanya untuk satu orang saja namun bisa ke berbagai banyak orang contohnya pesan melalui SMS ataupun internet

- Pesan yang di sampaikan bebas, tanpa harus melalui suatu Gatekeeper

- Pesan yang di sampaikan cenderung lebih cepat di banding media lainnya

- Penerima pesan yang menentukan waktu interaksi. ${ }^{[2]}$

Adapun Fitur-fitur yang harus terdapat pada sebuah aplikasi media sosial adalah sebagai berikut.

- Sociality yang dapat disebut sebuah komunitas fokus pada adanya pertukaran informasi.

- Openness yang biasanya tidak mempunyai jumlah pengguna yang ditentukan sebelumnya.

- Contributors merupakan seorang individu yangbebas dan tidak terikat dengan salah satu pihak atau lebih.

- Contents merupakan isi dari informasi yang dihasilkan dari sebuah media sosial

- Technology merupakan Sebuah aplikasi media sosial biasanya mudah digunakandan merupakan open source software

- Location yang pengguna aplikasi media sosial dapat berasal dari banyak lokasi asalkan terdapat koneksi internet. ${ }^{[1]}$

\section{B. Edraw Max}

Dalam website Edrawsoft dijelaskan bahwa Edraw max merupakan software untuk membuat diagram dan peta yang digunakan dengan sangat mudah dan hasil yang sangat bagus. Edraw max dilengkapi dengan fitur yang sempurna diantaranya, bagan organisasi, diagram dan grafik bisnis, tetapi juga diagram jaringan, rencana bangunan, peta pikiran, workflow, fashion desain, UML diagram, dan diagram teknik elekto. Fitur-fitur Edraw max seperti tampilannya menyerupai Microsoft Office 2010, terintegrasi dengan Microsoft Office, adanya tombol undo dan redo dll. ${ }^{[4]}$

\section{Sejarah Berdirinya Prodi Informatika UNSRAT}

Pada website Prodi Informatika dikatakan bahwa Program Studi Teknik Informatika (PSTI) di Jurusan Teknik Elektro (JTE) Fakultas Teknik (FT) Universitas 
Sam Ratulangi (UNSRAT), adalah merupakan pengembangan dari konsentrasi minat Teknik Informatika pada Program Studi Teknik Elektro (PSTE) di JTE FT UNSRAT. PSTI secara resmi mendapat ijin penyelenggaraan dari Direktur Jenderal Pendidikan Tinggi sebagaimana tertuang dalam Surat Keputusan Nomor 1689/D/T/2009 tanggal 17 September 2009, namun operasional kegiatannya baru dimulai pada bulan Juli tahun 2010 yang ditandai dengan penerimaan mahasiswa baru angkatan pertama sebanyak 83 orang, dengan kegiatan akademik mengacu pada kurikulum tahun 2008 yang disusun pada saat pengajuan proposal pembukaan program studi.. ${ }^{[7]}$

\section{Data Model}

Dalam buku Adam Boswort yang berjudul Designing Data-Intensive Web Applications dijelaskan bahwa tujuan dari pemodelan data memungkinkan spesifikasi data yang digunakan oleh aplikasi dengan cara formal. Hasil pemodelan data adalah skema konseptual yang menyampaikan cara yang sederhana dan mudah dibaca untuk pengetahuan yang tersedia dalam data aplikasi.

\section{1) Entitas}

Merupakan konsep utama dari model EntityRelationship. Entitas merupakan deskripsi dari fitur umum dari set objek. Contoh entitas seperti Orang, Mobil, Artis, dan Album. Atribut merupakan properti dari objek yang relevan untuk tujuan aplikasi. Contoh atribut nama, alamat, dan foto dari seseorang. Gambar berikut merupakan contoh entitas dan atribut dengan primary key
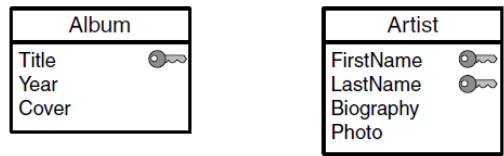

Gambar 1. Contoh Entitas

\section{2) Relationships}

Bentuk paling sederhana dari Relationships adalah hubungan biner, yang menghubungkan dua entitas. Setiap hubungan biner ditandai dengan dua peran hubungan, masing-masing mengekspresikan fungsi yang salah satu entitas yang berpartisipasi memainkan dalam hubungan. Gambar 2 menunjukkan notasi grafis untuk hub-ungan biner, yang diwakili oleh tepi berlabel menghubungkan kotak entitas. ${ }^{[3]}$

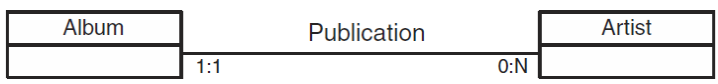

Gambar 2. Notasi grafis untuk Relationships

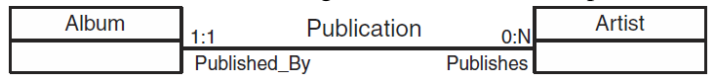

Gambar 3. Notasi grafis untuk Aturan Relationships

\section{E. Hypertext Model}

Dalam buku Adam Boswort yang berjudul Designing Data-Intensive Web Applications dijelaskan bahwa tujuan dari pemodelan hypertext adalah untuk menentukan organisasi antarmuka front-end dari aplikasi website. Berikut yang termasuk dalam hypertext model:

1) Unit

Merupakan unsur penting untuk menentukan isi dari halaman Web. WebML mendukung lima jenis unit yaitu Data units, Multidata units, Index units, Scroller units dan Entry units.

2) Pages

Merupakan elemen antarmuka yang sebenarnya dikirim ke pengguna, yang menelusuri hypertext dengan mengakses halaman dalam urutan yang diinginkan. Gambar 4 menunjukkan notasi WebML untuk Pages, yang hanya kotak berlabel mengelilingi unit milik page.
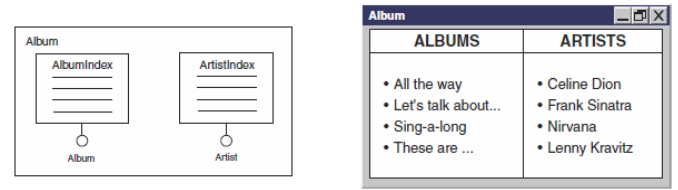

Gambar 4. Notasi WebML untuk Pages

3) Links

Baik halaman maupun unit eksis dalam isolasi, karena hypertext dunia nyata yang terbuat dari halaman yang terhubung, yang mengandung beberapa potong saling konten dan perintah memungkinkan pengguna untuk berinteraksi dengan aplikasi tersebut. ${ }^{[3]}$

\section{METODOLOGI PENELITIAN}

\section{A. Pengumpulan Data}

Teknik pengumpulan data dengan pertanyaan tertulis yang telah disusun sebelumnya. Pertanyaan yang terdapat dalam kuesioner, atau daftar pertanyaan tersebut cukup terperinci dan lengkap dan biasanya sudah menyediakan pilihan jawaban (kuesioner tertutup) atau memberikan kesempatan responden menjawab secara bebas (kuesioner terbuka). penulis mendapatkan bahwa di PSTI UNSRAT perlu ada website media sosial sendiri hal itu dapat dilihat dalam data kuesioner dibawah ini.

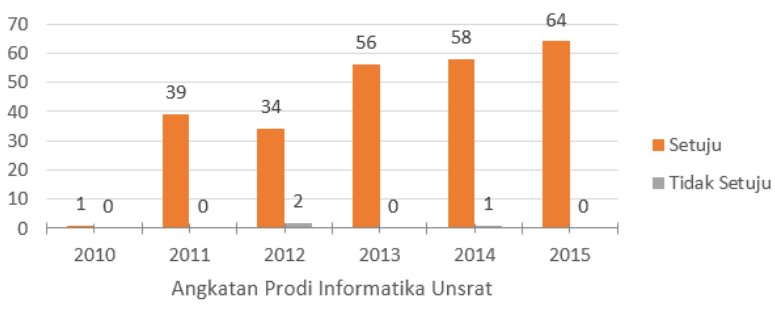

Gambar 5. Tanggapan tentang pembuatan Media Sosial sendiri (Data: Survey Kuisoner Penulis Terhadap 255 Responden) 


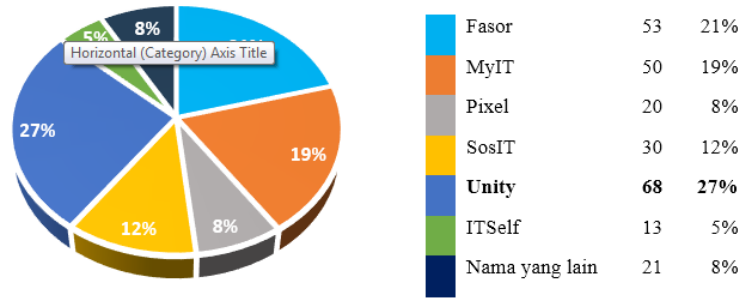

Gambar 6. Tanggapan tentang Pemberian Nama Pada Media Sosial (Data: Survey Kuisoner Penulis Terhadap 255 Responden)

B. Web Modeling Languange (WebML)

Menurut Janner Simarmata (2010:224), WebML merupakan bahasa spesifikasi tingkat tinggi untuk aplikasi hypermedia. WebML mengijinkan style keduanya, yaitu Entity-Relationship dan UML, untuk menawarkan notasi yang tepat dan representasi grafik menggunakan sintaks UML. ${ }^{[6]}$ Menurut Adam Bosword (2003:193) dalam bukunya yang berjudul "Designing Data-Intensive Web Application" WebML memungkinkan desainer untuk mengekspresikan fitur inti dari sebuah situs pada tingkat tinggi, tanpa melakukan rincian detail untuk arsitekturnya ${ }^{[3]}$

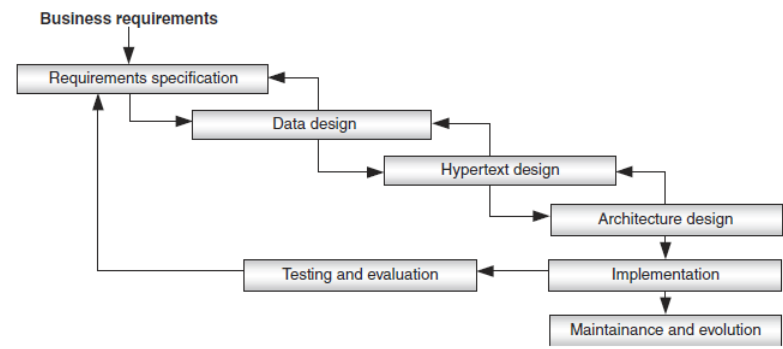

Gambar 7. Tahapan dalam proses pengembangan WebML

1) Requirements Specification

Merupakan kegiatan di mana analis aplikasi mengumpulkan dan meresmikan informasi penting tentang domain aplikasi dan fungsi yang diharapkan. Ada beberapa spesifikasi yang digunakan diantaranya Spesifikasi Grup, Spesifikasi Use Case, Spesifikasi Data, Spesifikasi Site View

\section{2) Data Design}

Merupakan fase di mana ahli data mengatur objek informasi utama yang diidentifikasi selama persyaratan spesifikasi menjadi model data konseptual yang comprehensive dan coherent. Proses data design ditunjukkan pada gambar 8 .

- Core sub-schema termasuk entitas dan hubungan yang menunjukkan konsep inti.

- Access sub-schemas terdiri dari entitas dan hubungan memainkan peran akses fasilitator.

- Interconnection sub-schema mencakup hubungan yang menghubungkan entitas inti.
- Personalization sub-schema menggabungkan pengguna dan kelompok entitas dan hubungan mereka dengan entitas inti.

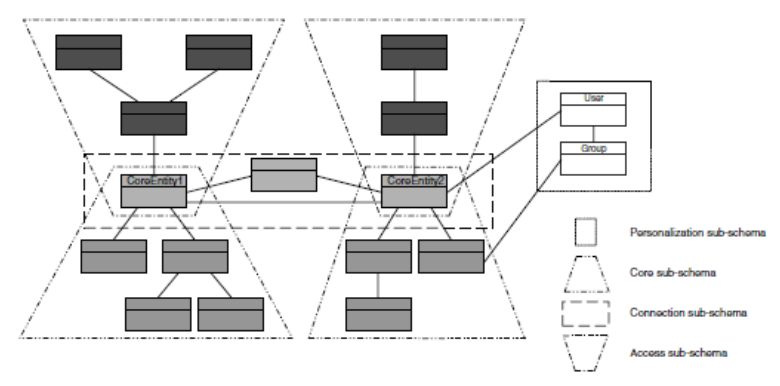

Gambar 8. Skema data untuk Access, core, interconnection dan personalization sub-schemas

\section{3) Hypertext Design}

Merupakan aktivitas yang mengubah persyaratan fungsional yang diidentifikasi dari requirements specification menjadi satu atau lebih tampilan situs. Pada gambar 9, sumber penting yaitu skema data konseptual yang mengungkapkan struktur data.

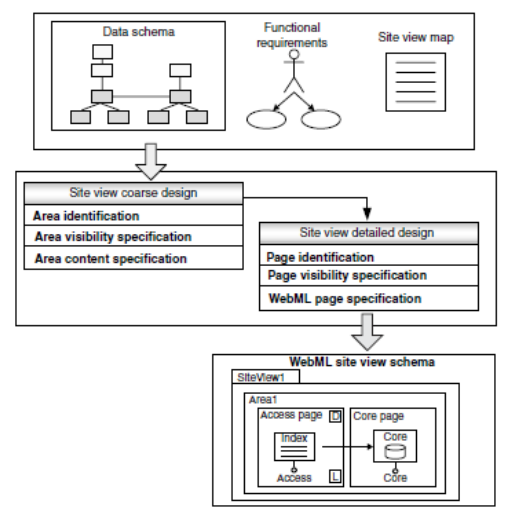

Gambar 9. Desain aktifitas Hypertext, input dan output.

\section{a. Desain kasar (Coarse Design)}

Desain kasar bertujuan untuk membangun sebuah draft pertama dari setiap tampilan situs, dengan memetakan unsur skema data ke area. Dari masukan ini, perancang menetapkan daftar konsolidasi situs tampilan daerah yang akan dikembangkan, dan menghasilkan representasi WebML pertama dari setiap site view yang terdapat pada gambar 10 .

- Default area, jika diakses secara default maka site view akan menyatakan diakses. Biasanya, salah satu daerah standar dalam tampilan site view adalah home page.

- Landmark area, Secara global dapat diakses dari area lain dalam situs web.

- Internal area, sesuai dengan hypertext yang dapat dicapai hanya dengan cara jelas, point-topoint navigasi link untuk beberapa halaman dari area lain. 


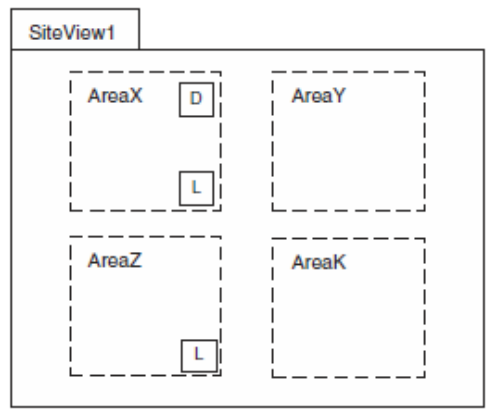

Gambar 10. Contoh peta site view dengan pembagian area.

\section{b. Detail design}

Merupakan penyempurnaan top-down dari desain kasar, di mana rancangan skema penayangan situs secara progresif direvisi sampai menjadi koleksi halaman WebML dan unit sesuai dengan kebutuhan pengguna. Definisi page visibility menunjuk setiap halaman sebagai home, default, landmark, atau internal page berdasarkan fungsinya masing-masing. ${ }^{[3]}$

\section{HASIL DAN PEMBAHASAN}

\section{A. Business Requirements}

Media sosial Prodi Informatika UNSRAT dirancang agar mahasiswa dan dosen Informatika UNSRAT dapat berinteraksi dalam hal saling tanya jawab seputar lingkungan Prodi Informatika dan pemberian informasi. Website media sosial Prodi Informatika memiliki 3 User diantarnya Mahasiswa, Dosen dan Alumni.

\section{B. Requirements Specification}

1) User Group

Gambar 11 menunjukan user group dari website media sosial Prodi Informatika, dibuat dalam bentuk hierarki.

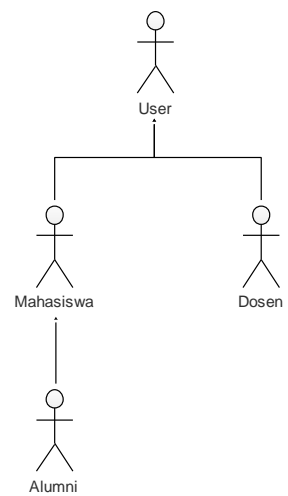

Gambar 11. User Group

\section{2) Functional Requirements}

Merupakan sarana untuk perancangan usecase yang akan digunakan dalam media sosial PSTI.

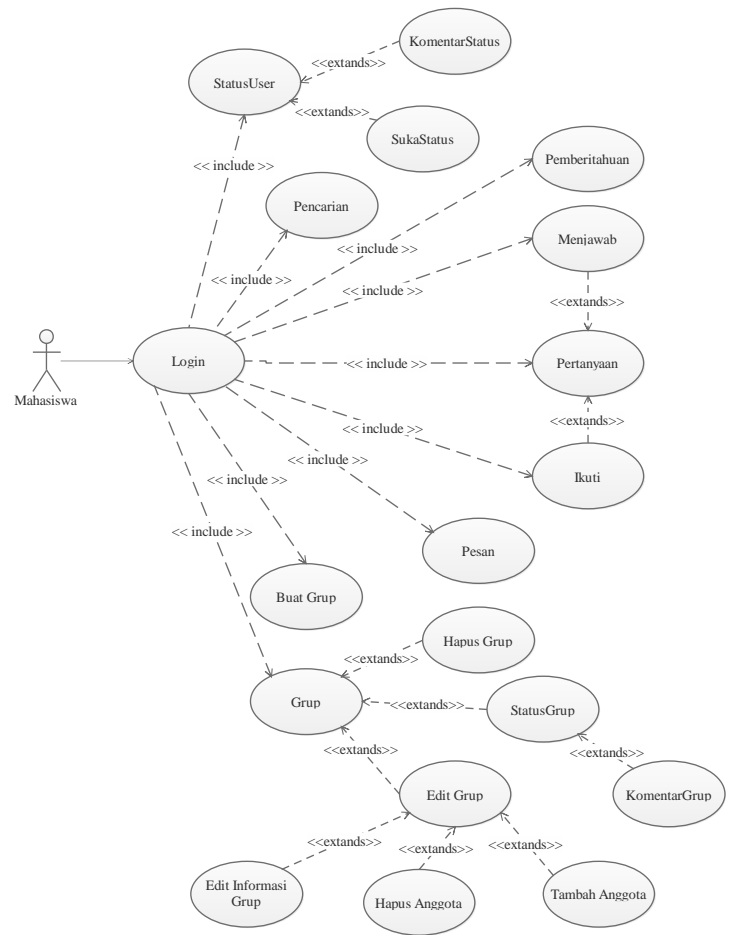

Gambar 12. Use case diagram untuk User Mahasiswa

\section{Data Design}

Merupakan sarana penting untuk mengklarifikasi database pada aplikasi. Membangun aplikasi Web tanpa mempertimbangkan kembali struktur data yang mendasari dapat menyebabkan persyaratan salah tafsir dan kesalahan desain.

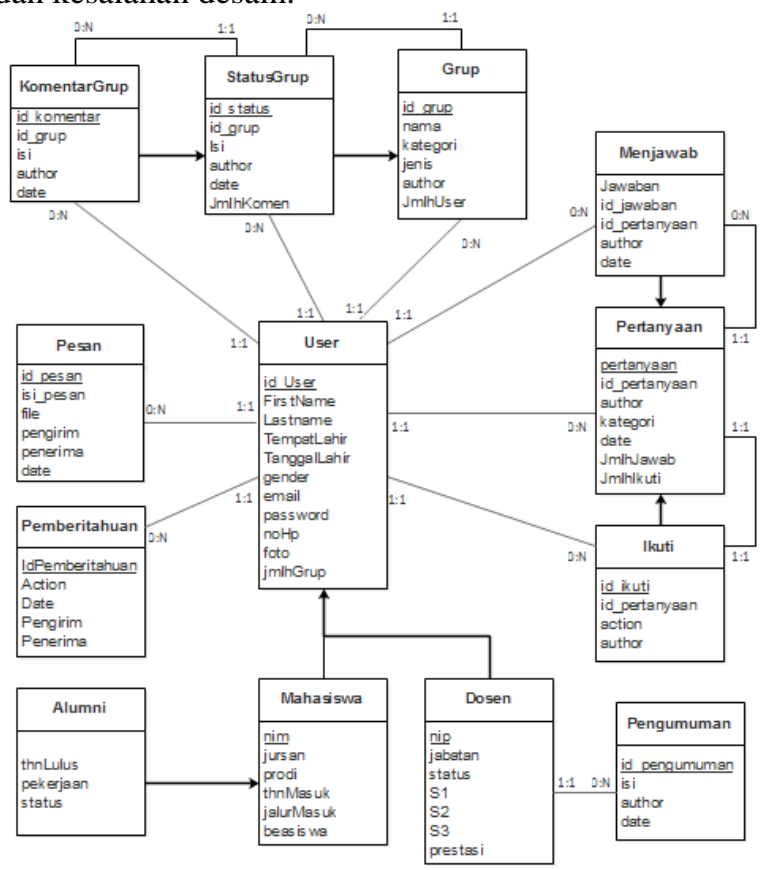

Gambar 13. Data Design untuk Media Sosial PSTI 


\section{Hypertext Design}

Dalam tampilan user terdapat isi berupa status yang bisa dikomentar atau disukai. Ada delapan area dalam tampilan ini yaitu Login, Beranda, Timeline Informasi, Grup, Profil, Pencarian, Pesan dan Pemberitahuan. Coarse Design untuk Users Site View dapat dilihat dalam gambar berikut.

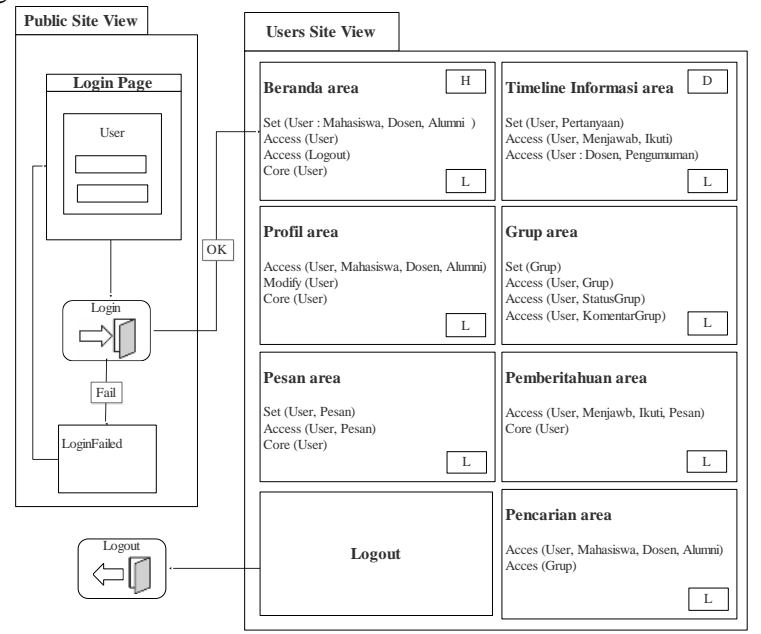

Gambar 14. Coarse design untuk User Site View

Area Beranda merupakan area utama pada media sosial PSTI, dapat diilustrasikan dalam gambar 15. Tampilan halaman home yang ada dalam beranda area ditunjukkan pada gambar 16.

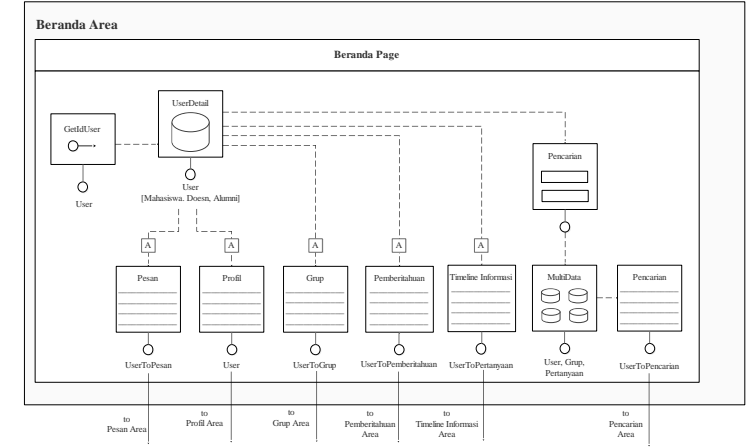

Gambar 15. Detailed hypertext schema untuk Beranda area

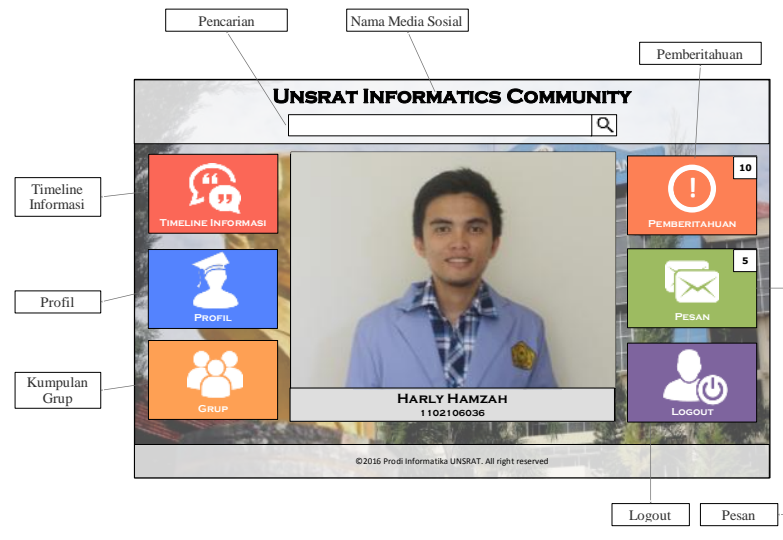

Gambar 16. Halaman Media Sosial PSTI
Area Timeline Informasi merupakan area default untuk tampilan pada media sosial PSTI. Detail hypertext schemas dapat diilustrasikan dalam gambar 17. Tampilan halaman timeline informasi yang ada dalam beranda area ditunjukkan pada gambar 18 .

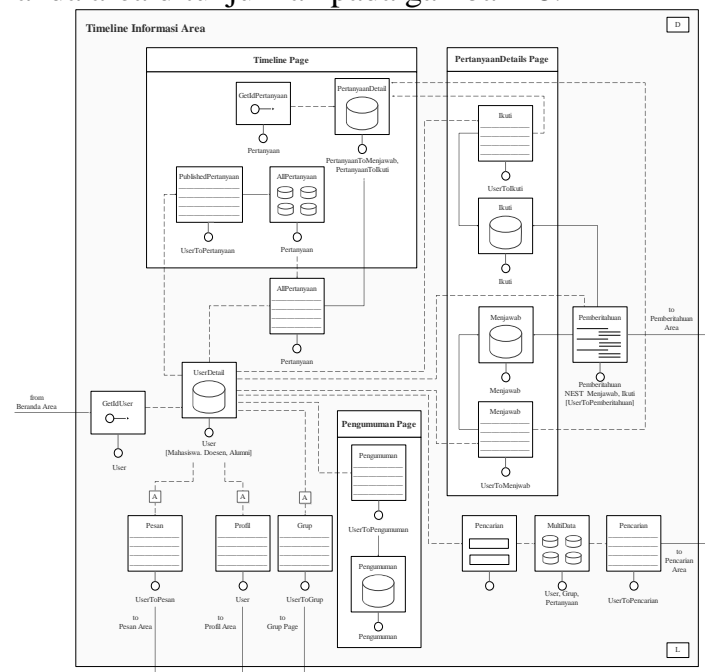

Gambar 17. Detailed hypertext schema untuk Timeline Informasi

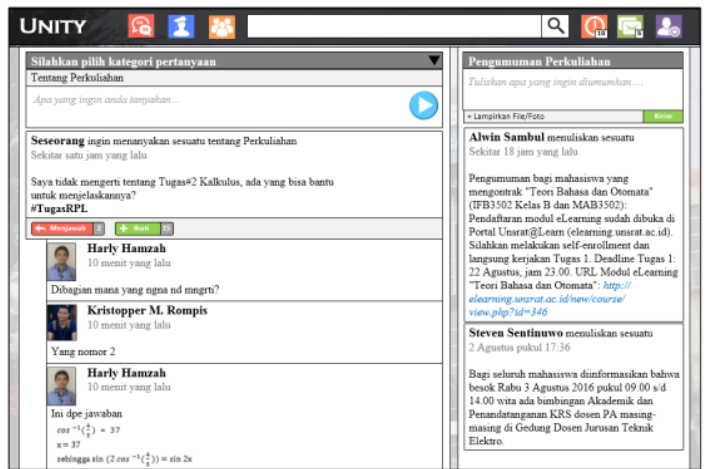

Gambar 18. Halaman Timeline Informasi untuk website media sosial

Area Grup merupakan area untuk menampilkan daftar grup yang dimiliki atau diikuti user dan juga bisa menambahkan grup baru, detail hypertext schemas dapat diilustrasikan dalam gambar 19. Tampilan halaman grup yang ada dalam grup area ditunjukkan pada gambar 20 .

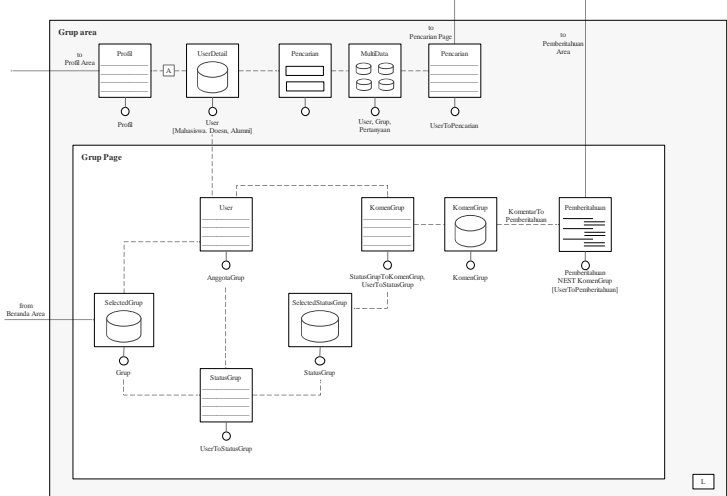

Gambar 19. Detailed hypertext schema untuk Grup area 


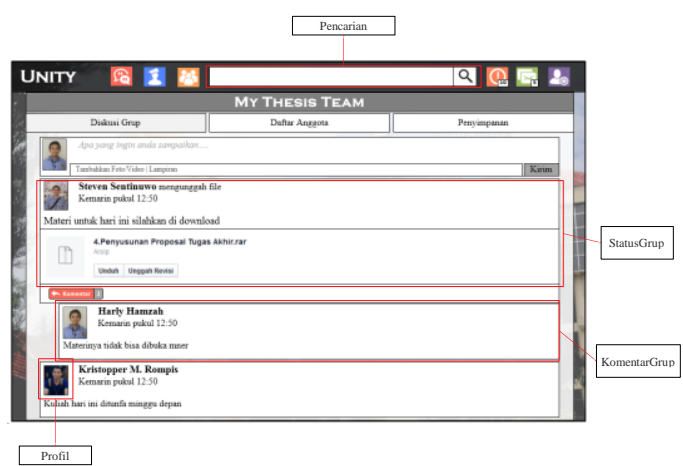

Gambar 20. Halaman Grup untuk website media sosial PSTI

Area Profil merupakan area untuk menampilkan identitas user. Detail hypertext schemas dapat diilustrasikan dalam gambar 21. Dan tampilan area profil ditunjukan pada gambar 22.

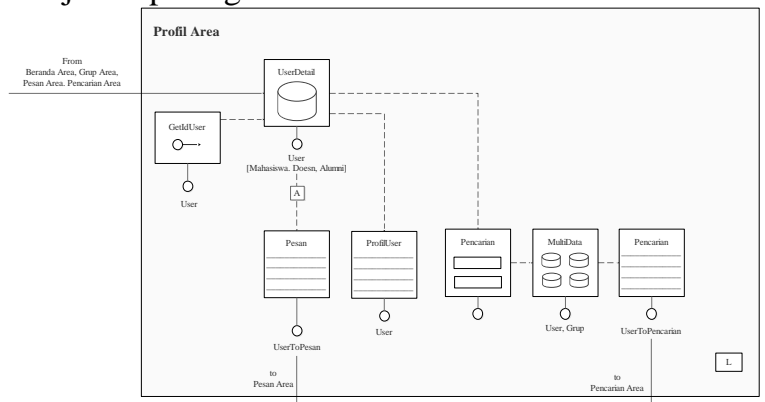

Gambar 21. Detailed hypertext schema untuk Profil area

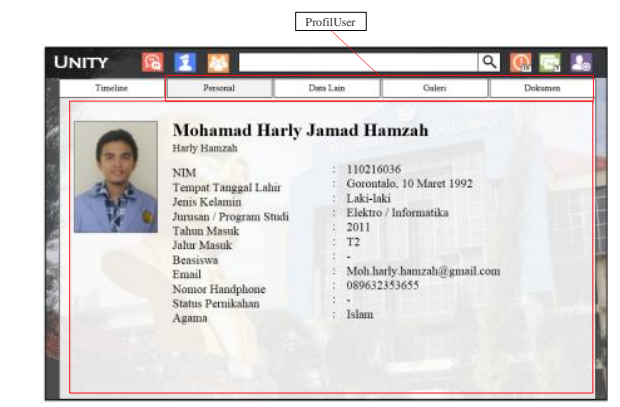

Gambar 22 Area Profil untuk website media sosial PSTI

\section{KESIMPULAN DAN SARAN}

\section{A. Kesimpulan}

Berdasarkan dari pembahasan-pembahasan pada bab-bab sebelumnya, maka dapat ditarik kesimpulan dari Analisa dan Perancangan Website Media Sosial (Studi Kasus Program Studi Informatika UNSRAT), yaitu Pada program studi informatika UNSRAT membutuhkan website media sosial untuk interaksi mahasiswa dan dosen dan pengguna website media sosial ini merupakan mahsiswa, dosen. Dari seluruh proses Web Modelling Language (WebML), data design dan hypertext merupakan hal yang paling berpengaruh dalam pembuatan website. Karena data design merupakan proses untuk menentukan database yang akan digunakan dalam website sedangka hypertext design merupakan design tampilan untuk website tersebut.
B. Saran

Saran yang ingin disampaikan untuk pengembangan lebih lanjut dalam penelitian ini adalah sebagai berikut:

1. Diharapkan pada pengembang agar dapat mengikuti sesuai dengan perancangan yang telah dibuat

2. Diharapkan untuk pengembangan selanjutnya bisa menambahkan fitur-fitur baru dalam perancangan media sosial ini seperti pertanyaan lebih dikategorikan dengan 5W1H: What, Where, When, Why, Who, How.

\section{DAFTAR PUSTAKA}

[1] Alkaff, F, dkk. 2013. Analisis dan Perancangan Perangkat Lunak Media Sosial untuk Berbagi Informasi Diskon. Teknik Informatika, Teknologi Informasi, Institut Teknologi Sepuluh Nopember (ITS).

[2] Azis, R. 2014. Analisis dan Perancangan Website Sosial Media untuk Anggota Himpunan Mahasiswa Teknik Informatika Yogyakarta (HIMATIKA). Sekolah Tinggi Manajemen Informatika dan Komputer AMIKOM Yogyakarta.

[3] Bosword, A. 2003. Designing Data-Intensive Web Applications. San Fransisco. United States of America.

[4] Edrawsoft, Edraw Max Pro. https://www.edrawsoft.com/EDraw Max.php, Diakses terakhir pada tanggal 15 Juni 2016.

[5] Mulyanti, A, dkk sebagai Tim Pusat Humas Kementrian Perdagangan RI. 2014. Panduan Optimalisasi Media Sosial untuk Kementerian Perdagangan RI. Jakarta Pusat.

[6] Simarmata, Janner. 2010. Rekayasa Web. Yogyakarta

[7] TI Unsrat Web Development Team, Sejarah Teknik Informatika Unsrat. http://fatek.unsrat.ac.id/informatika/index.php/tentangkami/profil, Diakses terakhir pada tanggal 15 Juni 2016.

[8] Widjonarko, A. PT Sebangsa Bersama, Sebangsa. https://sebangsa.com/about, Diakses terakhir pada tanggal 15 Juni 2016

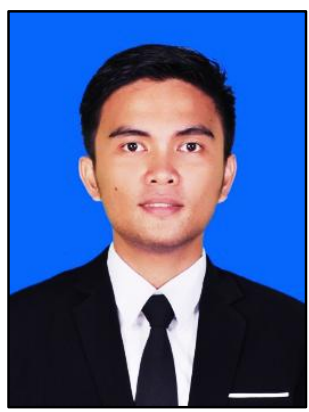

Mohamad Harly Jamad Hamzah lahir di Gorontalo 1992 Anak ke-1 dari 3 bersaudara. Dengan pendidikan Sekolah Dasar Negeri 5 Amurang. Kemudian Me-lanjutkan ke Sekolah Menengah Pertama SMP Negeri 1 Amurang Kemudian melanjutkan ke Sekolah Menengah Atas SMA Negeri 1 Amurang. Pada tahun 2011 memulai pendidikan di Fakultas Teknik Universitas Sam Ratulangi Manado di Jurusan Teknik Elektro Program Studi Informatika. Dalam menempuh pendidikan penulis juga pernah melaksanakan Kerja Praktek yang bertempat di Prodi Informatika UNSRAT pada bulan Februari 2015, penulis membuat Skripsi demi memenuhi syarat Sarjana (S1) dengan penelitian berjudul Analisa dan Perancangan Media Sosial (Studi Kasus Program Studi Informatika UNSRAT) yang dibimbing oleh dua dosen pembimbing yaitu Virginia Tulenan, S.Kom., MTI. dan Xaverius B. N. Najoan, ST., MT. Selesai melaksanakan pendidikan di Fakultas Teknik Elektro Program Studi Informatika Universitas Sam Ratulangi Manado pada September 2016 dengan menyandang gelar Sarjana Komputer dan mendapatkan predikat Sangat Memuaskan. 